Int. J. Dev. Biol. 52: 703-715 (2008)

doi: $10.1387 / \mathrm{ijdb} .082571 \mathrm{bs}$

\title{
Reassessing the role of protein-carbohydrate complementarity during sperm-egg interactions in the mouse
}

\author{
BARRY D. SHUR* \\ Department of Cell Biology, Emory University School of Medicine, Atlanta, GA 30322, USA
}

\begin{abstract}
Despite years of intense study by many investigators, it may appear that we have made little progress towards a molecular understanding of mammalian sperm binding to the egg zona pellucida. An abundance of evidence derived from in vitro assays suggests that sperm-zona pellucida binding is dependent upon sperm recognition of specific glycan moieties on the zona pellucida glycoproteins. However, there is considerable disagreement regarding the identity of the zona pellucida sugars thought to mediate sperm binding, as well as disagreement over the identity of the sperm receptors themselves. Moreover, results from in vivo gene-targeting strategies fail to support a role for many, if not all, of the sperm receptors and their zona pellucida ligands implicated from in vitro assays. Nevertheless, a retrospective view of the literature suggests that some common principles are emerging regarding the molecular basis of mammalian sperm-zona binding, both with respect to the nature of the components that mediate binding, as well as the involvement of distinct receptor-ligand interactions, that involve both protein- and carbohydrate-dependent mechanisms of binding.
\end{abstract}

KEY WORDS: sperm receptor, zona pellucida glycan, galactosyltransferase, ZP3, OGP, SED1

\section{Introduction}

Almost 100 years have passed since Lillie first postulated that gamete adhesion is mediated by interactions between complimentary molecules on the sperm and egg (Lillie, 1913). Over the ensuing years, this concept of gamete recognition has been reinforced by studies of a wide range of species, most notably marine invertebrates, which have identified sperm-bound proteins with high specificity for complex carbohydrate ligands in the egg coat (Neill and Vacquier, 2004). Subsequent studies of mammalian fertilization, using bovine, porcine and murine systems, also suggest that gamete adhesion is mediated by proteincarbohydrate recognition (Tulsiani et al., 1997). However, results using gene-targeting strategies have questioned the primacy of protein-carbohydrate complementarity in mammalian fertilization (Hoodbhoy and Dean, 2004; Williams et al., 2007), and at present there is no clear consensus regarding the molecular basis of gamete adhesion in mammals.

Many factors have contributed to this current state of affairs. Unlike marine invertebrates that shed large numbers of sperm and eggs, only limited quantities of mammalian eggs can be isolated. Furthermore, since marine invertebrates fertilize externally, the various aspects of fertilization can be recapitulated in vitro. In contrast, mammalian sperm and eggs undergo biochemical maturation in the female reproductive tract, some aspects of which can be mimicked in vitro. However, current in vitro assays of mammalian sperm-egg binding cannot fully replicate the complex, multifactorial processing of sperm and eggs that occurs in vivo. Furthermore, most in vitro assays fail to account for the presence of cumulus cells that sperm must traverse before reaching the egg coat, or zona pellucida ( $Z P)$. Adding to this complexity, is that mammalian sperm-egg binding is characterized by distinct phases, an initial loose attachment followed by tight binding between gametes, the biochemical basis of which remains obscure. Consequently, results of gene-targeting strategies that examine the role of candidate sperm receptors and zona ligands must be interpreted with caution as we do not fully understand how their expression and function are impacted by the complex array of biochemical and physiological modifications that occur in vivo.

Despite the inevitable limitations of both in vitro and in vivo approaches, some themes appear to be emerging that allow us to

Abbreviations used in this paper: Gal, galactose; GalT, galactosyltransferase; ZP, zona pellucida.

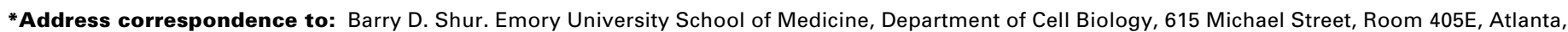
GA 30322 USA. Fax: +1-404-727-6256. e-mail: bshur@emory.edu
}

Published online: 4 July 2008

0214-6282/2008/\$35.00

(C) UBC Press

Printed in Spain 
formulate testable models of mammalian sperm binding to the ZP. This review will discuss the prevailing models of mammalian gamete recognition, focusing primarily on the mouse system due to its accessibility to both in vitro and in vivo strategies. Given the current debate, studies that either support or refute the involvement of protein-carbohydrate complementarity will be discussed. In this regard, studies of sperm $\beta 1,4$-galactosyltransferase (GaIT), a carbohydrate-binding protein implicated in binding to the ZP, will be reviewed, since much of these data address the relevance of carbohydrate recognition. Furthermore, studies of sperm GalT underscore an important role for reproductive tract secretions that associate with the maturing gametes and which appear critical for sperm-egg binding. The nature of these reproductive tract glycoproteins and how they participate in gamete recognition will be discussed as will a number of other candidate receptors for the ZP. In vitro studies suggest that sperm-egg binding is
mediated by protein-carbohydrate complementarity

\section{The zona pellucida glycoprotein ZP3 behaves as a sperm- binding ligand}

Pioneering studies by Wassarman and colleagues showed that the murine ZP is composed of three glycoproteins, referred to as ZP1, ZP2 and ZP3. Homologs are found in a wide range of mammalian eggs, some of which contain a fourth ZP glycoprotein not expressed in mouse (Hoodbhoy et al., 2005). Competitive in vitro-binding assays using individually purified ZP glycoproteins demonstrate that ZP3 isolated from unfertilized mouse eggs is able to competitively inhibit sperm binding to the intact ZP, whereas ZP1 and ZP2 cannot. Furthermore, ZP3 isolated from fertilized eggs, which no longer support sperm binding, fails to competitively inhibit sperm-egg binding (Bleil and Wassarman, 1980a,b). These observations indicated that ZP3 is responsible for the sperm-binding activity of the murine $\mathrm{ZP}$, and that its activity is lost following fertilization presumably due to the action of cortical granule enzymes released at egg activation. It is noteworthy that purified ZP3 binds specifically to the plasma membrane overlying the intact acrosome, consistent with the fact that only acrosome-intact sperm initiate binding with the ZP. In contrast, ZP2 selectively binds to acrosome-reacted sperm, suggesting that ZP2 may stabilize the adhesion of the acrosome-reacted sperm as it initiates penetration of the ZP (Mortillo and Wassarman, 1991). Similar to that described in mouse, ZP3 homologs also appear to possess sperm-binding activity in other mammalian systems (Tulsiani et al., 1997).

\section{O-glycans account for ZP3's sperm-binding activity}

Biochemical manipulation of purified ZP3 suggests that its sperm-binding activity is independent of the polypeptide backbone, as the activity is resistant to denaturants, mild proteolysis and other reagents that destroy the polypeptide. Similarly, activity is resistant to removal of $\mathrm{N}$-linked oligosaccharides by endo- $\mathrm{H}$ glycosidase digestion. In contrast, activity is lost following alkali release of the Olinked sugar chains, suggesting that ZP3's sperm-binding activity resides on its $O$-linked glycans (Florman and Wassarman, 1985). In support of this, the released $O$-linked oligosaccharides bind to sperm and competitively inhibit spermzona binding. Unfortunately, there is considerable disagreement regarding the nature of the sugar epitopes on $O$-linked glycans responsible for sperm-binding activity (discussed below).

\section{ZP3 binding elicits the acrosome reaction}

Sperm binding to the ZP elicits the acrosome reaction, an exocytotic event in which the sperm plasma membrane fuses with the underlying outer acrosomal membrane, exposing the acrosomal contents that facilitate penetration of the ZP (Bleil and Wassarman, 1983). As expected of a sperm receptor, purified ZP3 elicits the acrosome reaction, although the individual spermbinding oligosaccharides do not. These and other studies indicate that ZP3 induces the acrosome reaction by cross-linking its receptor in the sperm membrane, eliciting intracellular signal cascades culminating in acrosomal exocytosis (Florman et al., 1999). The best studied among these are a pertussis toxin (PTx)sensitive heterotrimeric G-protein (Ward and Kopf, 1993), and a voltage-independent cation channel that regulates membrane potential, which in turn regulates a voltage-dependent cation channel (Florman et al., 1999). These cascades, among others, result in elevated intracellular calcium and $\mathrm{pH}$ that are required for acrosomal exocytosis. Sperm binding to the ZP also activates a sperm glycine receptor/chloride channel that may contribute to the control of voltage-sensitive calcium influx (Meizel, 1997).

Although it is clear that soluble ZP3, among other ZP3 agonists, can induce acrosomal exocytosis in vitro, Dean and colleagues report that sperm can remain acrosome-intact on the ZP for hours (Baibakov et al., 2007). They argue that this lengthy "dwell" time of acrosome-intact sperm on the ZP speaks against a classic receptor-mediated signal transduction cascade in response to ZP3 binding. Rather, they argue that sperm employ a mechanosensory transducer that is activated upon forward thrust into the zona matrix. Since these studies utilized sperm with EGFP-filled acrosomes to enable identification of acrosome intact and reacted sperm, it is unclear to what degree the presence of EGFP influences the normal kinetics of acrosomal induction. Nevertheless, mechanosensory signaling is widespread in nature (Orr et al., 2006), and may very well contribute towards induction of the acrosome reaction.

\section{Sperm GalT serves as a signal transducing receptor for ZP3}

A wide variety of sperm surface components have been implicated in binding to the ZP, but only a few have been suggested to function as receptors for ZP3 (Leyton and Saling, 1989; Bleil and Wassarman, 1990). Of these, $\beta 1,4-$ galactosyltransferase (GalT) appears to satisfy the criteria expected of a ZP3 receptor (Shur et al., 2006). Like most glycosyltransferases, GalT is normally confined to the intracellular membranes where it participates in glycoprotein biosynthesis by transferring galactose (Gal), from UDP-Gal, to terminal $N$ acetylglucosamine (GIcNAc) residues on the growing polysaccharide chain. However, GalT is also expressed on the surface of selected cell types, most likely the consequence of an alternative cytoplasmic domain, where it functions as a carbohydrate-binding protein rather than as a biosynthetic enzyme (Rodeheffer and Shur, 2002).

GalT first appears uniformly distributed on the surface of pachytene spermatocytes, but is eventually redistributed to the dorsal, anterior aspect of the sperm plasma membrane (Scully et al., 1987) where it behaves as a traditional integral membrane 
protein (Shur and Neely, 1988). Since mature sperm no longer undergo protein synthesis, they no longer posses intracellular pools of GalT. Consequently, sperm are unique in that all of their GalT is confined to the plasma membrane overlying the intact acrosome. In the epididymis, sperm GalT is masked by epididymal glycosides possessing a polylactosamine (Gal $\beta 1,4 \mathrm{GlcNAc})_{n}$ core structure, which are subsequently shed from the sperm surface during capacitation (Shur and Hall, 1982a). The exposed GalT is now able to interact with its putative GlcNActerminating ligand on the ZP (Shur and Hall, 1982b; Miller et al., 1992). The released polylactosamine glycans competitively inhibit sperm-egg binding when added back to sperm-egg binding assays, and pretreatment with $\mathrm{N}$-acetylglucosaminidase (GlcNAc'dase) to remove the terminal GIcNAc residue, destroys its sperm-binding activity.

Further evidence that GalT participates in sperm binding to the ZP came from studies that took advantage of GalT's catalytic properties. For example, the addition to UDP-Gal leads to the dissociation of preformed sperm-egg adhesions by forcing the catalytic reaction to completion, thereby dissociating sperm GalT from its galactosylated product in the ZP (Lopez et al., 1985). Parallel assays with UDP- ${ }^{3}[\mathrm{H}] \mathrm{Gal}$ demonstrate that sperm are able to ${ }^{3}[\mathrm{H}]$ galactosylate ZP substrates when presented in either intact or soluble form. Similarly, pretreating the intact ZP with GlcNAc'dase to remove the sperm GalT substrate results in reduced sperm binding. Finally, sperm-egg binding is inhibited by $\alpha$-lactalbumin, a milk protein that reduces GalT affinity for GIcNAc substrates while increasing affinity towards glucose in order to synthesize milk sugar, or lactose (Shur and Hall, 1982b). These studies suggest that sperm GalT participates in sperm binding to the ZP, but its glycoprotein substrate, or ligand, in the ZP remained uncharacterized.

\section{Sperm GalT selectively recognizes the sperm- binding glycans on ZP3}

Following the identification of ZP3 as the zona receptor for sperm, and the implication that spermbinding activity is conferred by a class of $O$-linked glycan chains, it became of interest to determine whether ZP3, and specifically its sperm-binding $O$ linked glycans, serve as substrate for sperm GalT. This was addressed by incubating sperm GalT with ZP and UDP- ${ }^{3}[\mathrm{H}] \mathrm{Gal}$ to tag the GalT substrates in the ZP with ${ }^{3}[\mathrm{H}] \mathrm{Gal}$. Sperm GalT selectively ${ }^{3}[\mathrm{H}]$ galactosylates ZP3, but not ZP1 nor ZP2, whereas all three ZP glycoproteins are labeled if soluble GalT purified from milk is used instead of sperm GalT (Miller et al., 1992) (Fig. 1A). Thus, sperm GalT has strict substrate specificity towards ZP3. The ${ }^{3}[\mathrm{H}]$ galactosylated ZP3 glycans are sensitive to mild oxidation suggesting they are Olinked, similar to the sperm-binding glycans. More directly, the sperm-binding activity of purified ZP3 can be abolished by consuming its GalT-binding site by pregalactosylation using purified GalT and UDP-Gal (Fig. $1 \mathrm{C})$. Similarly, pretreatment of purified ZP3 with GlcNAc'dase to remove the GalT binding site leads to a loss of ZP3 sperm-binding activity (Fig. 1D). All of these studies indicate that sperm GalT selectively binds the same glycans on ZP3 that have spermbinding activity, as assayed in vitro (Miller et al., 1992).

Since ZP3 looses its sperm-binding activity following fertiliza-
A

$M_{\mathrm{r}}(\mathrm{K})$

C

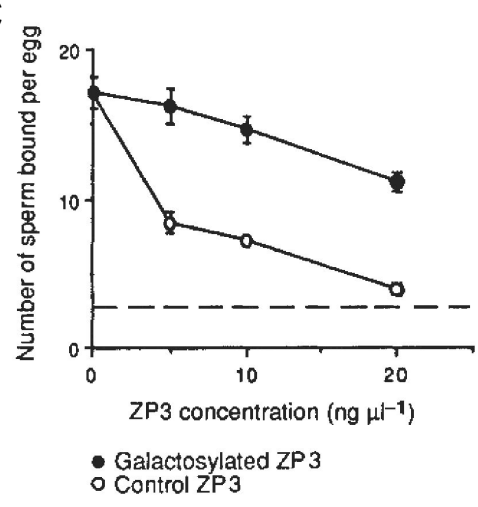

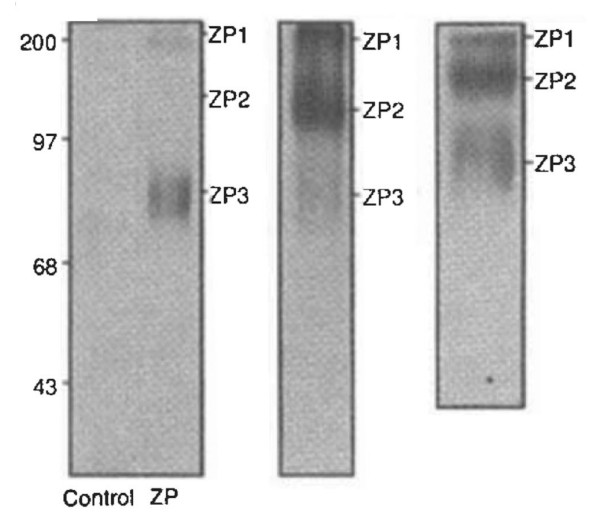

B
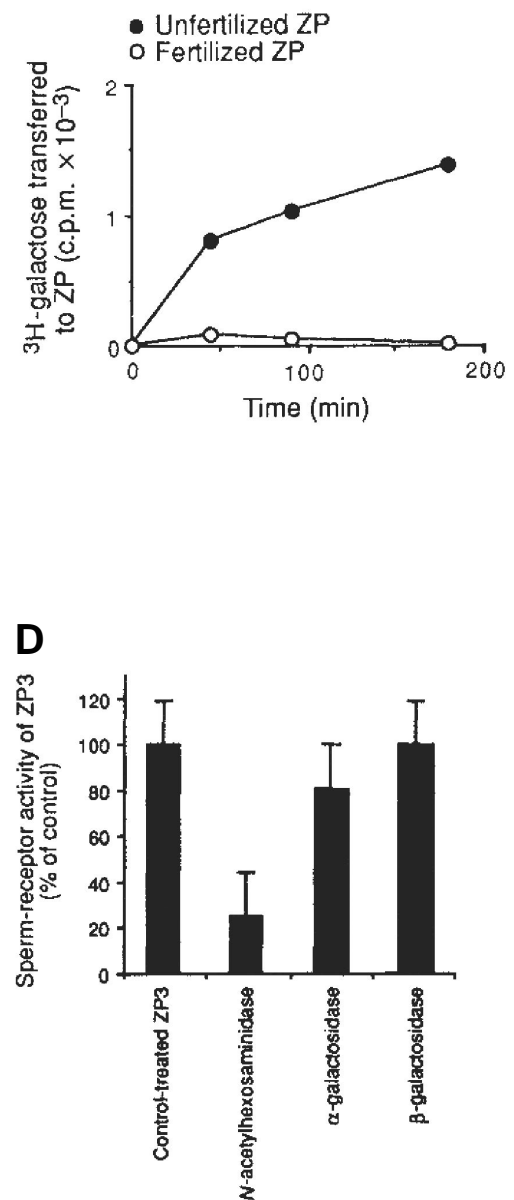

Fig. 1. Sperm galactosyltransferase (GaIT) selectively recognizes glycoside substrates on ZP3 from fertilized eggs, although non-sperm GalT binds all ZP glycoproteins. (A) (Left panel) Intact sperm and UDP-3[H]Gal were incubated with (ZP) or without (control) heat-solubilized ZP glycoproteins and the reaction products analyzed by SDS-PAGE and fluorography. Sperm GalT selectively binds and ${ }^{3}[H]$ galactosylates ZP3 glycans, but not $Z P 1$ or ZP2. (Middle panel) The absence of ${ }^{3}[\mathrm{H}]$ labeling of $Z P 1$ and $Z P 2$ is not the result of proteolysis during the incubation, as judged by parallel assays containing ${ }^{125}$-ZP glycoproteins incubated with sperm and unlabeled UDPGal. All three ZP glycoproteins remain intact during the incubation. (Right panel) Substituting sperm GalT with affinity-purified milk GalT results in ${ }^{3}[\mathrm{H}]$ galactosylation of all three ZP glycoproteins, illustrating the strict substrate specificity of sperm GalT towards ZP3 substrates. (B) Kinetics of sperm GalT ${ }^{3}[\mathrm{H}]$ galactosylation of ZP glycoproteins isolated from unfertilized and fertilized oocytes. In contrast to the presence of GalT substrates in unfertilized ZP, ZP collected from fertilized eggs no longer possess GalT substrates. (C) Consuming the GalT binding site in purified ZP3 by pregalactosylation with GalT and UDPGal destroys its sperm-binding activity. Control assays performed $n$ parallel included heat-inactivated GalT. The level of sperm binding to 2cell embryos is indicated by the dotted line. (D) Similarly, removing the GalT binding site in ZP3 by GIcNAc'dase pretreatment destroys its sperm-binding activity, whereas pretreatment with $\alpha$ - or $\beta$-galactosidase has little effect (adapted from Miller et al., 1992). 
tion, one may predict that ZP3 from fertilized eggs no longer possesses binding sites, or substrates, for sperm GalT. This was shown to be the case as demonstrated by the inability of sperm GalT to bind and galactosylate ZP isolated from fertilized eggs, in contrast to the abundant GalT activity towards ZP isolated from unfertilized eggs (Miller et al., 1992) (Fig. 1B). The loss of ZP3's sperm-binding and GalT substrate activity may reflect the action of the cortical granule enzymes released at fertilization and thought to participate in the block to polyspermy. It is therefore of interest that cortical granules release very high levels of GlcNAc'dase ( 15-times higher than other glycosidase) at fertilization, the same enzymatic activity used in vitro to destroy the GalT binding site on ZP3. In this regard, selective inhibition of cortical granule GlcNAc'dase overcomes the block to polyspermic binding that normally accompanies fertilization (Miller et al., 1993).

\section{Manipulating sperm GalT expression has predictable conse- quences on ZP3 binding}

If GalT serves as a receptor for ZP3, then ectopic expression of GalT on the surface of heterologous cells may lead to the binding of ZP3, but not other ZP glycoproteins. Consistent with this, injection of constructs encoding murine GalT into Xenopus oocytes leads to GalT expression on the oocyte plasma membrane and subsequent binding of ZP3 to GalT-expressing oocytes (Shi et al., 2001) (Fig. 2A). Oocytes expressing GalT do not bind ZP2 nor does ZP3 bind to non-injected oocytes. Similarly, overexpression of GalT in transgenic mice leads to sperm with elevated GalT on their plasma membranes and increased binding of radiolabeled ZP3 (Youakim et al., 1994). Finally, sperm from mice bearing targeted mutations in the GalT gene, and which no longer express GalT on their surface, are unable to bind radiolabeled ZP3 as well as wild-type sperm (Lu and Shur, 1997). Control assays eliminate the possibility that reduced ZP3 binding is the secondary consequence of altered intracellular glycosylation during spermatogenesis. These studies show directly that sperm GalT functions as a receptor for ZP3.

\section{Evidence implicating sperm GalT as an inducer of acrosomal exocytosis}

As discussed above, ZP3 binding is thought to induce acrosomal exocytosis by crosslinking or aggregating its receptor on the sperm membrane, which elicits intracellular signal cascades including activation of a PTx-sensitive heterotrimeric G-protein complex. As predicted of a ZP3 receptor, aggregation of GalT with anti-GalT IgG leads to acrosomal exocytosis and is inhibited by PTx, whereas monovalent Fab fragments do not unless crosslinked with a secondary antibody (Macek et al., 1991). Similar results are found using synthetic polymers containing multivalent GlcNAc. In Xenopus oocytes expressing murine GalT on their surface, binding of ZP3 or crosslinking GalT with IgG induces PTx-sensitive Gprotein activation and triggers cortical granule exocytosis and egg activation (Shi et al., 2001) (Fig. 2B). Similarly, membranes from transgenic sperm overexpressing GalT show increased rates of both basal and ZP-dependent G-protein activation, relative to wild-type sperm, and transgenic sperm show greatly accelerated rates of acrosomal exocytosis (Gong et al., 1995). Thus, increasing GalT expression on sperm makes them hypersensitive to their ZP3 ligand. Finally, GalT-null sperm that bind ZP3 poorly fail to undergo ZP-induced acrosomal exocytosis, although they respond normally to calcium ionophore that induces acrosomal exocytosis by bypassing the requirement for ZP3 binding (Lu and Shur, 1997).

It was surprising that a single-pass transmembrane protein like GalT is able to activate heterotrimeric G-proteins that are normally activated by heptahelical receptors. However, studies by others indicate that some single-pass receptors are able to activate heterotrimeric G-proteins due to a G-protein activation motif similar to that in heptahelical receptors (Okamoto et al., 1990; Okamoto et al., 1993; Nishimoto et al., 1993; Wade et al.,
A

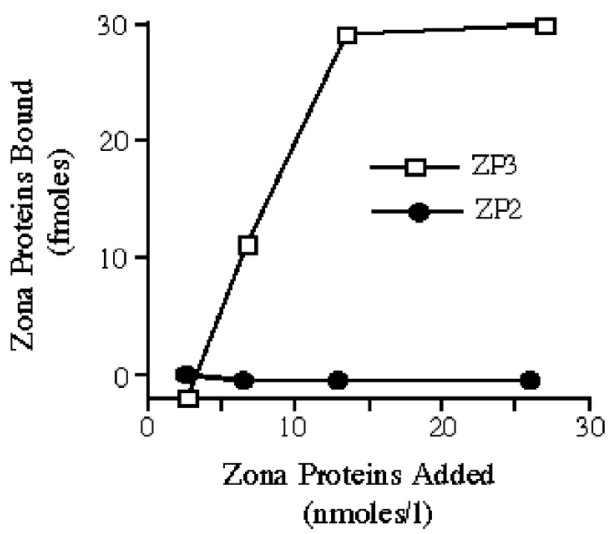

B
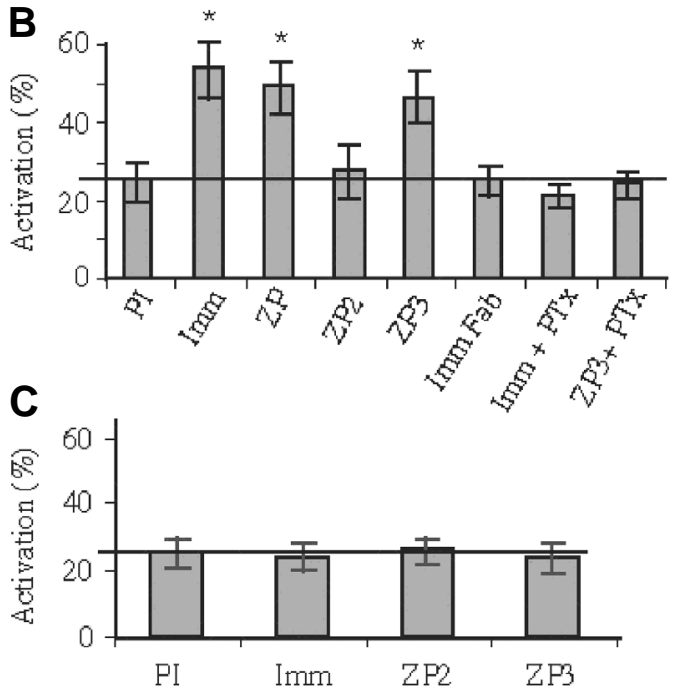

Fig. 2. Sperm GalT expression in Xenopus oocytes leads to ZP3-dependent egg activation. (A) $Z P 3$, but not $Z P 2$, binds to Xenopus oocytes expressing murine GalT on their surface. Increasing concentrations of each zona glycoprotein were added to Xenopus oocytes expressing GalT and water-injected control eggs. With increasing zona protein concentration, ZP3 binding increased to saturation, but ZP2 binding did not differ between RNA-injected and water-injected eggs. In this ZP3 preparation, the $K_{D}$ was approximately $9 \mathrm{nM}$ but affinity was variable between ZP3 preparations. (B) GalT agonists activate Xenopus eggs expressing murine GalT. The addition of total ZP glycoproteins, ZP3, or GalT antibodies (Imm) to eggs expressing GalT triggers cortical granule exocytosis, cortical contraction and

vitelline envelope elevation. Preimmune antibodies (PI), monovalent $F_{a b}$ fragments (Imm $F_{a b}$ ) or ZP2 produce background activation rates. Pertussis toxin (PTX) pretreatment of eggs prevents activation. asterisk $=P<0.01$. (C) Eggs expressing murine GalT with a mutation in the putative $G$ protein binding domain do not activate in response to GalT agonists. The horizontal line represents control levels of egg activation. (adapted from Shi et al., 2001) 
1999). The ability of this motif to bind and activate heterotrimeric G-proteins is regulated by serine/threonine phosphorylation (Sun et al., 1995). In this regard, the cytoplasmic domain of surface GalT contains the predicted G-protein activation motif, and peptides corresponding to the cytoplasmic domain are able to bind PTx-sensitive G-protein subunits, whereas scrambled sequences are not (Gong et al., 1995). In Xenopus oocytes expressing GalT on their surface, mutagenesis of the G-protein activation motif in the GalT cytoplasmic domain eliminates G-protein activation in response to ZP3 or anti-GalT IgG (Shi et al., 2001) (Fig. 2C). Recent studies indicate that G-protein activation by the GalT cytoplasmic domain is regulated by serine phosphorylation (unpublished), similar to that reported for other single-pass receptors (Sun et al., 1995).

All of these observations clearly indicate that sperm GalT functions as a signal transducing receptor for ZP3. Others have confirmed the participation of GalT during mouse sperm-egg binding (Benau et al., 1990) and GalT has been detected on the surface of all mammalian sperm thus far assayed, including rat, guinea pig, rabbit, equine, bovine, porcine and human (FayerHosken et al., 1991; Larson and Miller, 1997; Huszar et al., 1997) although its role, if any, during sperm-ZP binding in these species remains unknown.

\section{Sperm from GalT-null males still bind to the ZP and are fertile}

In light of the abundant evidence that GalT functions as a receptor for sperm-binding glycans on ZP3, it was surprising that GalT-null sperm still bind to the intact ZP even though they bind ZP3 poorly. Similarly, GalT-null males are fertile despite the inability of GalT-null sperm to undergo a ZP-induced acrosome reaction (Lu and Shur, 1997). The acrosome reaction has traditionally been viewed as a prerequisite for sperm penetration through the ZP; however, sperm null for the acrosomal protease, acrosin, are also fertile (Baba et al., 1994). Although both of these observations suggest that the entire ZP3/GalT/G-protein-activated release of acrosomal contents is dispensable for fertilization, it is noteworthy that the efficacy of in vitro fertilization is greatly diminished for both GalT-null and acrosin-null males; GalT-null sperm penetrate and fertilize the oocyte only $7 \%$ of wildtype levels, and acrosin-null sperm show reduced rates of zona penetration. Thus, in a noncompetitive environment where all sperm are phenotypically similar, as in the GalT-null male, a few sperm appear to find their way through the ZP (presumably via low levels of spontaneous acrosome reactions) and fertilize the egg. However, when compared to wild-type sperm, this process is extremely inefficient, suggesting that in a competitive environment the integrity of the GalT/ZP3/acrosome induction complex may be advantageous for successful fertilization. This has been shown to be the case for acrosin-null sperm, since when they are mixed with wild-type sperm, either by mixed inseminations or in chimeric testes, the wild-type sperm compete out the ability of acrosin-null sperm to fertilize eggs (Adham et al., 1997).

\section{Analysis of GalT-null sperm distinguishes initial ga- mete adhesion from induction of the acrosome reac- tion}

In any event, the ability of GalT-null sperm to bind the ZP implies that sperm-egg binding likely involves at least two distinct events: a GalT/ZP3-independent mechanism that mediates initial gamete adhesion, followed by ZP3-dependent aggregation of GalT leading to acrosomal exocytosis. Conceptually, this paradigm is similar to the concerted action of selectins and integrins during lymphocyte adhesion to the endothelium (Sackstein, 2005). It is, therefore, not unreasonable to expect that successful binding of sperm and eggs may be dependent upon the sequential action of distinct receptor-ligand interactions that stabilize the gametes as they encounter one another in a dynamic fluid environment. As discussed below, studies using GalT-null sperm facilitated the identification of accessory glycoproteins that participate in initial gamete adhesion.

\section{The nature of the sperm-binding carbohydrates in the $Z P$ remains undefined}

Regardless of the role played by GalT in sperm-ZP binding, studies above clearly indicate that sperm binding to the ZP, as assayed in vitro, involves sperm recognition of glycan chains on the ZP3 polypeptide. Studies implicating GalT as a receptor for ZP3 glycans predict that the terminal sugar residue recognized by sperm is GlcNAc, the sugar acceptor substrate for GalT. A number of observations are consistent with this, such as the ability of sperm to bind to Sepharose beads coated with GlcNActerminating neoglycoproteins (Bendahmane and Tulsiani, 2003), the loss of ZP3's sperm-binding activity following GlcNAc'dase treatment or pregalactosylation (Miller et al., 1992), and the ability of GIcNAc'dase pretreatment to destroy the sperm-binding activity of large molecular weight polylactosamine glycans (Shur and Hall, 1982a).

However, a variety of observations argue against a primary role for terminal GIcNAc as a sperm-binding epitope on the ZP, but rather suggest sperm recognize terminal mannose and/or Gal residues. For example, low molecular weight glycans with terminal GlcNAc fail to competitively inhibit sperm-egg binding in vitro, whereas glycans terminating in mannose (Cornwall et al., 1991) or Gal, either Gal $\alpha 1,3 \mathrm{Gal} \beta 1,4 \mathrm{GlcNAc}$ or Gal $\beta 1,4 \mathrm{GlcNAc}$ (Litscher etal., 1995; Johnston et al., 1998), are potent inhibitors of binding, as are their $\alpha 1,3$-fucosylated derivatives (Johnston et al., 1998; Kerr etal., 2004). That at least some of these sugar structures are capable of binding sperm is shown by the ability of mouse sperm to bind immobilized neoglycoproteins terminating in mannose (Bendahmane and Tulsiani, 2003) as well as terminal $\beta$ Gal residues of asialofetuin (Mori et al., 1997).

At the simplest level, all of these data support the hypothesis that sperm bind to specific glycan structures on the ZP, presumably on ZP3. However, similar approaches by different investigators have failed to reach a consensus regarding the terminal sugar that presumably plays a critical role in sperm binding. In vitro competition studies suggest sperm recognize terminal Gal and mannose epitopes, but studies using large molecular weight glycans, rather than soluble glycoside inhibitors, also suggest a role for terminal GIcNAc. Irregardless, the use of defined oligosaccharides to competitively inhibit sperm-zona binding must be interpreted with caution, since the degree and type of oligosaccharide branching can affect the ability of the terminal sugar to competitively inhibit sperm-egg binding. This raises the possibility that negative results may simply result from an inappropriate presentation of the terminal sugar, such that it is not recognized 
by the sperm receptor (Litscher etal., 1995; Clark and Dell, 2006). Furthermore, immunocytochemical analysis reveals that the sugar composition of the ZP is heterogeneous (Avilés et al., 1997; Avilés et al., 2000). Some sugar moieties, such as $\alpha$-Gal and $N$ acetylgalactosamine (GalNAc) are confined to the inner portions of the mature ZP, whereas other sugars, such as GlcNAc, are dispersed uniformly throughout the zona. The spatial heterogeneity of zona glycosides makes it impossible to know whether soluble glycosides added as competitors of sperm-zona binding necessarily mimic glycans available to sperm at initial binding, or rather, during later aspects of zona penetration. Some sugar epitopes that competitively inhibit sperm binding in vitro, such as Lewis X fucosyl residues, are not present anywhere in the ovarian or ovulated mouse ZP, making it unlikely they participate in sperm-egg interactions (Avilés et al., 2000). Nevertheless, the inhibitory activity of Lewis $\mathrm{X}$ glycosides suggests they may mimic a structurally similar epitope in the ZP.

Whereas some studies have employed soluble sugars as competitive inhibitors, others have approached the identity of the sperm-binding glycan by glycosidase treatment of the intact ZP or of purified ZP3, or by sperm binding to glycans immobilized on beads. Some investigators have reported that the sperm-binding activity of purified ZP3 is sensitive to pretreatment with GlcNAc'dase, but not to $\alpha$ - or $\beta$-galactosidase treatment (Miller et al., 1992); whereas others have reported sensitivity to $\alpha$-galactosidase but not to GlcNAc'dase (Bleil and Wassarman, 1988). Similarly inconsistent results have been reported for the ability of exo-glycosidases to remove sperm-binding sires on the intact ZP (Shur and Hall, 1982b; Mori etal., 1997). Further complicating this issue, is the suggestion that $N$-linked glycans also participate in mouse sperm binding, in addition to $O$-linked glycans, since treatment of the intact ZP (as opposed to purified ZP3) with $N$ glycanase inhibits subsequent sperm binding (Yamagata, 1985). In this regard, $N$-linked glycans have been implicated in the binding of porcine and bovine sperm to the egg ZP (Yonezawa et al., 1995; Yonezawa et al., 2007).

Some of this inconsistency may reflect the fact that there appears to be at least two distinct binding events during the early stages of sperm-egg interaction, one of which is mediated by ZP3 and the other by a ZP3-independent glycoprotein adsorbed onto the ZP at ovulation (discussed below). Consequently, it is unknown if the glycan under study is participating in the ZP3 dependent or independent phase of sperm binding.

\section{Structural characterization of the oligosaccharide chains on murine ZP glycoproteins}

Presumably, knowledge of the carbohydrate structures present in the ZP would help clarify this issue by providing a catalogue of the potential sperm-binding glycans, as well as a means to eliminate sugars implicated in binding but which are undetectable in the mouse ZP. The structural characterization of the $\mathrm{N}$ - and $\mathrm{O}$ linked glycans of the mouse $Z \mathrm{P}$, as well as those present on purified ZP2 and ZP3 glycoproteins, has been undertaken by a number of investigators. Although not all reports are in complete agreement, and the details that distinguish the different approaches and results are beyond the scope of this article, some generalities are evident and are discussed below. Nevertheless, it is important to keep in mind that investigators have had to resort to ovaries as a source of ZP glycoproteins, as ovulated oocytes generate insufficient material for analysis. Since immunocytochemical studies indicate differential glycosylation of the ZP glycoproteins during maturation (Avilés et al., 1997; Avilés et al., 2000 ), the relative contribution of the various sugar chains identified in ovarian ZP, composed of all follicular stages, is likely to be distinct from those expressed on the surface of the mature ZP. Despite these inevitable limitations, the characterization of ZP glycans offers a first glimpse into the possible sperm-binding structures.

\section{N-linked sugars}

The bulk of evidence indicates the presence of high mannose $N$-glycans and branched complex-type $N$-linked glycans, many with polylactosamine core structures terminating in $\beta$ Gal, $\alpha-G a l$, and GlcNAc moieties, although the relative occurrence of these terminal sugars differ among reports (Tulsiani et al., 1992; Noguchi and Nakano, 1993; Nagdas et al., 1994; Tulsiani, 2000; Easton et al., 2000). The presence of terminal sialic acid and GalNAc residues has also been reported. Although most evidence favors sperm recognition of $O$-linked glycans, the ability of $N$-glycanase to remove sperm binding sites on the mouse ZP (Yamagata, 1985) indicates that the sugar-binding properties of the $N$-linked glycans should be given more attention. In this regard, sperm-ZP binding in both bovine and porcine appears to be mediated by $N$-linked glycans, specifically high mannose and complex-type branched chains, respectively (Yonezawa et al., 2007). Similarly, the suggestion that mouse sperm recognize high mannose $N$ linked glycans (Cornwall et al., 1991) is supported by the presence of high mannose glycans in ZP3.

\section{O-linked glycans}

The majority of the O-glycans found in the mouse ZP are confined to ZP3, consistent with studies cited above indicating that ZP3's sperm-binding activity is due to O-linked sugar chains. Early studies using exo-glycosidase digestions and lectin chromatography identified a predominant $O$-linked glycan of ZP3 as the trisaccharide GIcNAc-Gal $\beta 1,3$ GalNAc (Nagdas et al., 1994), consistent with GalT recognition of terminal GIcNAc residues on $O$-linked glycans of ZP3. Recent structural analyses confirmed the presence of a similar $O$-linked trisaccharide on ZP3, although identification of the terminal hexosamine as GalNAc or GIcNAc remains unknown. Nevertheless, the predominant $O$-linked structures are Core 2 type, i.e., $\beta 1,6 \mathrm{GlcNAc}$ branched chains with terminal or exposed sialic acid, hexosamine (either GlcNAc or GalNAc), Gal $\beta 1,4 \mathrm{GlcNAc}$, GalNAc $\beta 1,4 \mathrm{GlcNAc}$, GalNAc $\beta 1,4 \mathrm{Gal}$, and Gal $\alpha 1,3 \mathrm{Gal}$ structures (Easton et al., 2000; Dell et al., 2003).

It seems that virtually all of the sugars found in terminal, or non-reducing, positions of ZP3 glycan chains have been implicated in sperm binding. Nevertheless, most observations are consistent with sperm binding to lactosamine containing glycans that are presumably $\mathcal{O}$-linked, although $N$-linked glycans have abundant lactosamine chains and have been implicated in sperm binding in mouse, bovine, and porcine. Whether the terminal structure most closely resembles Gal $1,3 \mathrm{Gal}$; Gal $\beta 1,4 \mathrm{GlcNAc}$; or GlcNAc is less clear, although the bulk of evidence implicates $\beta \mathrm{Gal}$ and to a lesser degree, GlcNAc. It is 
interesting that some $N$ - and $O$-linked chains possess the GalNAc $\beta 1,4 \mathrm{Gal}$ epitope, which may be confined to the inner portion of the ZP (Avilés et al., 1999) and participate in secondary aspects of sperm binding and/or penetration (Cahová and Dráber, 1992).

\section{Results of gene swapping and targeted deletion stud- ies question the role of carbohydrate-mediated ga- mete recognition}

\section{Replacement of murine ZP glycoproteins with their human homologs has no effect on mouse-specific sperm binding}

If ZP3 is the authentic species-specific receptor for sperm binding, then substituting human (hu) ZP3 for mouse (mo) ZP3 in mouse oocytes may confer human sperm-specific binding to mouse eggs. This approach has been undertaken by Dean, Rankin and colleagues who have examined the consequences of replacing the mouse ZP polypeptides with their human homologs. However, in light of evidence that ZP3's spermbinding activity is conferred by specific glycan chains, replacing the mouse polypeptide with human homologs may have little consequence as the glycans that decorate the polypeptide backbone are synthesized posttranslationally by mouse oocyte glycosyltransferases. Not surprisingly, therefore, replacing moZP3 with hu-ZP3 (Rankin et al., 1998), or replacing all three ZP polypeptides with their human counterparts (Hoodbhoy and Dean, 2004), has no effect on species-specific sperm binding. As expected, structural studies confirm that similar glycan structures are synthesized on both mouse and human ZP3 polypeptides when expressed in mouse oocytes (Dell et al., 2003; Chalabi et al., 2006).

Although these results are consistent with species-specific sperm binding to glycan chains of ZP glycoproteins, mouse eggs containing hu-ZP2 continue to support sperm binding after fertilization, unlike normal eggs that no longer support binding after egg activation. The "zona" block to polyspermy is associated with, among other changes, cleavage of ZP2 by a protease released from cortical granules (Bleil and Wassarman, $1980 a, b)$. It is, therefore, noteworthy that the ability of eggs expressing hu-ZP2 to support sperm binding after fertilization is correlated with a failure of hu-ZP2 to undergo proteolytic cleavage, even though the cortical reaction occurs normally. From these and other results, Dean and colleagues suggest that sperm recognize a supramolecular scaffold composed of both ZP2 and ZP3, rather than specific glycan chains on ZP3 (Hoodbhoy and Dean, 2004). After fertilization, they hypothesize that cleavage of ZP2 results in loss of the macromolecular structure and a concomitant loss of sperm binding. Since huZP2 is not cleaved at fertilization, despite the normal proteolysis of mo-ZP2 when both polypeptides are present in the same oocyte, it appears that the mouse protease is incapable of cleaving the hu-ZP2 polypeptide, thus accounting for the continued binding of sperm to fertilized eggs expressing hu-ZP2. The authors argue that if sperm binding is dependent upon ZP3 glycans, then the released cortical granule enzymes should have destroyed the sperm-binding glycosides. However, many carbohydrate-modifying enzymes recognize binding sites within the polypeptide backbone as well as the sugar chain, and therefore, the cortical granule glycosidases may not recognize their glycan substrates in the context of the human polypeptide, similar to the apparent inability of the mouse protease to cleave hu-ZP2. Furthermore, since ZP2 and ZP3 are thought to interact and form multimers, it is unclear how the presence of any human ZP protein interferes with the overall architecture of the mouse zona and the function of the individual glycoproteins.

\section{Removing glycans from the $Z P$ has little effect on fertility}

A more direct approach to testing the requirement of specific glycan residues in sperm-egg binding has been undertaken by Stanley and coworkers (Shi et al., 2004; Williams et al., 2007). Complex-type $N$-linked glycans or $O$-linked glycans were eliminated from the ZP glycoproteins via oocyte-specific deletion of the appropriate glycosyltransferases, and the consequences on fertility, and in some cases on sperm-egg binding, were examined. Despite the abundant in vitro evidence implicating ZP glycans in sperm binding, oocytes containing no detectable complex $N$-linked glycans or $O$-linked glycans are fertilized and produce viable offspring. The loss of $N$-linked glycans results in thinner ZP than controls and reduced sperm binding, but nevertheless, the level of binding is sufficient for fertilization. The elimination of $O$-linked sugars has no obvious effect on fertility in vivo or sperm-egg binding in vitro, though the latter was not quantified. In any event, the fact that oocytes containing only the $O$-linked core sugar, GalNAc, and/or high mannose $N$ glycans can be fertilized indicates that many of the terminal epitopes implicated in sperm binding, such as lactosamine disaccharides and GIcNAc, are not essential for fertilization. Whether the residual high mannose $N$-linked glycans are responsible for sperm binding in these glycosyltransferase-deficient oocytes remains unknown.

Finally, a significant complication of these in vivo genetargeting approaches is that sperm binding is assayed to ovulated eggs, which possess a ZP3-independent sperm-binding ligand that may obscure any differences due to the replacement of mouse ZP genes and/or elimination of ZP glycans (Rodeheffer and Shur, 2004). In this light, the most rigorous test of the modified ZP glycoproteins is to assay individually purified glycoproteins for sperm-binding activity in competitive binding assays, as is routinely performed in mouse. One would predict that mouse oocytes expressing hu-ZP3 should be an effective competitor of sperm-egg binding, based upon the presence of similar $O$-linked glycans on mouse and human ZP3 polypeptides when expressed in mouse oocytes. It would be particularly interesting to assay the sperm-binding activity of ZP3 isolated from oocytes that are unable to synthesize complex-type $N$ linked glycans or $O$-linked structures. Presumably, the underglycosylated ZP3 would fail to competitively inhibit sperm-egg binding, since chemically deglycosylated ZP3 no longer inhibits binding (Florman and Wassarman, 1985). This would argue that the complexities and redundancies that characterize fertilization in vivo are able to accommodate alterations to the ZP once the sperm are caught between the cumulus cells and ZP. In this regard, it has recently become clear that gamete recognition in mammals involves a multiplicity of binding mechanisms, some of which may be mediated by carbohydrate recognition and others dependent upon protein-protein interactions. Furthermore, there is reason to believe that accessory binding mechanisms exist that supplement the role of ZP3 in sperm 
binding, and which rely upon reproductive tract glycoproteins that facilitate initial gamete adhesion (Rodeheffer and Shur, 2004; Ensslin and Shur, 2003).

\section{Receptors that bind protein as well as carbohydrate epitopes have been identified on sperm and sug- gested to mediate binding to the ZP}

Given the conflicting evidence regarding carbohydrate-mediated recognition in sperm binding to the $\mathrm{ZP}$, it is not surprising that investigators have reported the presence of sperm receptors that recognize protein, as well as carbohydrate, epitopes on the ZP. Of those receptors thought to bind carbohydrate epitopes, GalT is the most extensively studied, but it now appears unlikely that GalT participates in initial gamete adhesion (Lu and Shur, 1997). Perhaps of more relevance to initial gamete binding, receptors for both mannosyl and galactosyl sugars have also been reported on mammalian sperm.

\section{Carbohydrate-binding receptors for the ZP}

Tulsiani, Orgebin-Crist and colleagues have characterized a novel plasma membrane-associated $\alpha$-mannosidase on mouse, rat, hamster and human sperm that is enzymatically and immunologically distinct from the acidic mannosidases found in the intracellular compartments (Tulsiani et al., 1989; Cornwall et al., 1991). That this novel mannosidase may participate in sperm-ZP binding is supported by the presence of high mannose $N$-linked glycans on ZP3, and by the ability of competitive substrates to concomitantly inhibit sperm mannosidase activity and sperm-egg binding in vitro. The consequences of targeted deletions in this novel, sperm surface $\alpha$-mannosidase have yet to be reported.

The suggestion that terminal Gal residues on ZP3 participate in sperm binding predicts the presence of Gal-binding proteins on the sperm surface. In this regard, Kierszenbaum and colleagues have reported the presence of rat hepatic lectin $(\mathrm{RHL})$ 2/3, a C-type lectin with specificity for Gal and GalNAc residues, on the surface of rat and human sperm (Abdullah and Kierszenbaum, 1989; Rivkin et al., 2000). Immunoreactive $\mathrm{RHL} 2 / 3$ is found on both the sperm tail and head membranes, and antibodies directed against the carbohydrate recognition domain inhibit fertilization of rat oocytes in vitro. However, high concentrations of antibody are required for inhibition and it is not known what stage of fertilization is blocked by the antiserum. Given the strong evidence implicating terminal Gal residues in sperm-ZP binding, the presence of a Gal-binding protein on the sperm surface is intriguing and deserves more attention.

Another putative Gal-binding protein reported on mouse, rat and human sperm is fucosyltransferase (FucT). Biochemical and subcellular fractionation studies indicate that a number of FucT activities are present on the plasma membrane of mouse spermatogenic cells and epididymal sperm, including $\alpha 1,2$ and $\alpha 1,3 / 4$ FucTs that transfer fucose to $\mathrm{Gal}$ and GIcNAc substrates, respectively (Ma et al., 2006). Similar to that reported for sperm GalT, the great majority of FucT activity is confined to the sperm surface. The ability of substrates for $\alpha 1,2$ and $\alpha 1,3 /$ 4 FucTs, such as Galß1,4GIcNAc, to inhibit sperm-egg binding is consistent with a role for sperm FucT in recognition of ZP glycans (Litscher et al., 1995; Thaler and Cardullo, 1996; Johnston et al., 1998).

A significant advance in this area was recently reported by Yeung and coworkers, who identified $\alpha 1,3 / 4$ FucT as the receptor on human sperm for Glycodelin-A (Chiu et al., 2007). Glycodelin-A is a protein secreted by the endometrium that binds to sperm and competitively inhibits sperm binding to the human ZP. The binding activity of Glycodelin-A is believed to be conferred by its glycan chains, which terminate in Gal $\beta 1,4 \mathrm{GlcNAc}$ and GalNAc $\beta 1,4 \mathrm{GlcNAc}$ residues, both potent substrates for $\alpha 1,3 / 4 \mathrm{FucT}$ (Dell et al., 1995). The specific $\alpha 1,3 / 4 \mathrm{FucT}$ responsible for binding Glycodelin-A was identified as FUT5 by mass spectrometry sequencing and by reactivity with anti-FUT5 antibodies. Consistent with earlier reports, FucT is confined to the plasma membrane of human sperm, and anti-FucT antibodies and competitive substrates inhibit human sperm binding to Glycodelin-A and to the ZP. Furthermore, FucT purified from human sperm binds to the ZP with high affinity. These and other results raise the intriguing possibility that FucT serves as a ZP receptor in human, mouse, as well as other mammals. Consistent with this, the FucT substrates Gal $\beta 1,3 \mathrm{GlcNAc}$, Gal $\beta 1,4 \mathrm{GlcNAc}$ and GalNAc $\beta 1,4 \mathrm{GlcNAc}$ have all been reported in the mouse ZP (Easton et al., 2000; Dell et al., 2003). Although targeted deletions in mouse $\alpha 1,3 / 4 \mathrm{FucT}$ s have little effect on male fertility (Ma et al., 1996), their participation in gamete binding should not discounted until the consequences of gene-targeting strategies are better understood.

\section{Protein based recognition during sperm-ZP binding}

The ability of sperm to bind and fertilize oocytes with glycandeficient ZP raises the possibility that sperm-zona binding also requires carbohydrate-independent mechanisms. In this regard, it is interesting that carbohydrate-based reagents rarely inhibit sperm-egg binding completely, suggesting that the concentration and/or affinity of the competitive ligand may be suboptimal, or alternatively, that some aspect of binding is independent of carbohydrate-based mechanisms.

The most compelling evidence in support of protein-based recognition during gamete binding comes from studies of the ADAM family of metalloproteases, some of which show testisspecific expression. Targeted deletions in two testis-specific ADAMs, ADAM1 and ADAM2, lead to defects in sperm transport into the oviduct and in sperm binding to the ZP. However, subsequent studies suggest these defects are likely the secondary consequence of defective ADAM-dependent protein processing during spermatogenesis (Nishimura et al., 2007). In marked contrast, targeted deletions in ADAM3, also known as cyritestin, result in normal sperm migration into the oviduct, but sperm still fail to bind the ZP (Shamsadin et al., 1999; Nishimura et al., 2001). Furthermore, unlike ADAM1 and ADAM2 that function in the endoplasmic reticulum and possibly on the cell surface as well, ADAM3 is a cell surface protein. Thus, the inability of ADAM3-null sperm to bind the ZP strongly suggests that ADAM3 plays a direct, as opposed to a processing role, in sperm binding to the ZP. Although the ADAM3-binding epitopes in the ZP are unknown, peptides corresponding to the disintegrin domain in ADAM3 bind to the ZP and competitively inhibit sperm-ZP binding (Shamsadin et al., 1999), further suggesting that ADAM3 serves a critical function in sperm-ZP binding. 
Another sperm protein implicated in binding to the ZP is CRISP1, an epididymal protein that binds to the sperm head and which has previously been implicated in mediating fusion between the acrosome-reacted sperm and the oolema. However, prior to the acrosome reaction, CRISP1 immunoreactivity is localized on the dorsal aspect of the sperm head, a location suggestive of a role in binding to the ZP. The ability of antiCRISP1 antibodies and native CRISP protein to competitively inhibit sperm binding to the ZP is consistent with this possibility, although the nature by which CRISP is thought to facilitate binding remains unclear (Busso et al., 2007).

Finally, the current debate regarding the relevance of protein-based vs. carbohydrate-based mechanisms of sperm-ZP binding do not adequately consider the possible involvement of stereospecific charged residues as a platform for sperm-egg interactions. As will be discussed below, stereospecific polysulfations appear to be the basis for gamete recognition in marine invertebrates and may also explain how newly identified epididymal components facilitate sperm binding to the ZP. Studies by Tanphaichitr and colleagues in the porcine system have suggested that sulfogalactosylglycerolipid (SGG) mediates binding to the ZP via electrostatic interactions between the sulfated galactosyl residues of SGG and glycoside moieties of zona glycoproteins (White et al., 2000). These weak electrostatic interactions may be facilitated by arylsulfatase $A$, a sperm-associated enzyme that is thought to aid in the initial binding of SGG to zona glycosides (Khalil et al., 2006).

\section{Initial gamete adhesion is facilitated by glycopro- teins secreted from the female and male reproductive tracts}

\section{Ovulated egg coats have a peripherally-associated, ZP3- independent sperm-binding ligand}

The ability of GalT-null sperm to bind the ovulated ZP, but not soluble ZP3, suggests the presence of a ZP3-independent sperm-binding ligand on the ovulated egg. This was confirmed by comparing the sperm-binding activity of egg coats isolated from ovarian and ovulated oocytes. As reported, ovarian ZP glycoproteins inhibit the binding of wild-type sperm to ovulated eggs; however, they fail to competitively inhibit GalT-null sperm binding to eggs, consistent with the inability of GalT-null sperm to bind ZP3 (Lu and Shur, 1997; Rodeheffer and Shur, 2004). In marked contrast, zona glycoproteins isolated from ovulated oocytes inhibit both wild-type and GalT-null sperm binding to the ZP. Thus, as predicted, the ovulated ZP contains a ligand to which both wild-type and GalT-null sperm bind and which is absent from the ovarian ZP (Rodeheffer and Shur, 2004).

Further characterization of the ZP3-independent ligand on ovulated eggs indicates that it is peripherally-associated with the zona matrix, presumably adsorbed from oviduct secretions at ovulation. It behaves as a $\sim 250 \mathrm{kDa}$, WGA-reactive glycoprotein with a basic isoelectric point, distinguishing it from the acidic glycoproteins that form the insoluble matrix of the ZP (Rodeheffer and Shur, 2004). There is extensive literature regarding oviduct-secreted glycoproteins that bind to the zona matrix at ovulation (Malette et al., 1995; Verhage et al., 1998), the best characterized being Oviduct Secreted Glycoprotein (OGP) (Sendai et al., 1995). However, OGP-null females are fertile and retain the ZP3-independent ligand, indicating they are distinct gene products (Araki et al., 2003; Rodeheffer and Shur, 2004). The identity of the ZP3-independent ligand awaits further characterization.

\section{Identification of sperm SED1/MFG-E8 as an adhesin for the $Z P$}

Among the many sperm proteins implicated as receptors for the egg coat, as opposed to receptors specifically for ZP3 glycosides, two are of particular interest: zonadhesin and p47. Originally identified in the pig, zonadhesin is a sperm protein that binds to the ZP in a species-specific manner (Hardy and Garbers, 1995). Subsequent studies indicated that zonadhesin is localized in the acrosomal matrix, rather than on the sperm plasma membrane (Hardy, 2000). Thus, zonadhesin may mediate the binding of sperm to the egg coat during early stages of acrosomal exocytosis, rather than during initial sperm-egg binding. This possibility awaits testing.

p47, a peripherally-associated sperm surface protein, was identified by affinity chromatography of solubilized boar sperm plasma membranes applied to immobilized porcine ZP glycoproteins (Ensslin et al., 1998). p47 displays a mosaic structure with two amino-terminal EGF-like repeats followed by two domains with high similarity to the $\mathrm{C} 2$ domains of blood clotting factors $\mathrm{V}$ and VIII. The second EGF-like domain contains an RGD sequence, a motif often found in integrin ligands. To assess the function of p47 during fertilization, the mouse homolog was cloned and renamed SED1 to indicate that it is a Secreted protein that contains Notch-like EGF repeats and Discoidin/F5/8 type C (discoidin/C) domains. Sequence analysis shows SED1 to be identical to a previously identified milk protein, MFG-E8, now known to participate in a variety of cell-cell and cell-matrix interactions (Shur et al., 2004).

In mouse, SED1 is localized to the Golgi complex of spermatogenic cells, from which it is likely secreted. However, the predominant source of SED1 appears to be the initial segment of the caput epididymis, where it is secreted and coats the sperm head overlying the acrosome, presumably by intercalation of the discoidin/C domains into the plasma membrane bilayer. SED1derivatized beads bind selectively to the ZP of unfertilized oocytes by virtue of the discoidin/C domains, but do not bind to zona of fertilized eggs. Recombinant SED1 and anti-SED1 antibodies competitively inhibit sperm-egg binding, as do truncated SED1 proteins containing a discoidin/C domain, all suggestive of a role for SED1 in sperm adhesion to the ZP (Ensslin and Shur, 2003).

The participation of SED1 during sperm-egg binding was confirmed by analysis of SED1-null male mice, which are subfertile and produce litter sizes $\sim 1 / 3$ of control littermates, ranging from no pups (sterility) to near normal. In vitro assays demonstrate a near complete inability of SED1-null sperm to bind to ZP of ovulated eggs. Importantly, SED1-null males show normal mating behavior and normal sperm morphology, number, motility and ability to undergo acrosomal exocytosis. These studies clearly demonstrate a role for SED1 during initial sperm-egg adhesion (Ensslin and Shur, 2003). Preliminary blot overlay assays suggests that SED1 binds to ZP3 and to a lesser extent to ZP2, although a more detailed analysis of the ZP ligands for SED1 is required. Presumably, SED1 is docking to sialylated and/or sulfated complex carbohydrate residues in ZP3 (and possibly ZP2), 
since the binding specificity of discoidin/ $\mathrm{C}$ domains is dictated by hypervariable loops that dock with negatively charged phospholipids and/or carbohydrates (Fuentes-Prior et al., 2002).

The GalT-null mouse was instrumental in dissecting spermegg binding into two distinct molecular events: a GalT/ZP3independent interaction that contributes to initial gamete adhesion, and ZP3-dependent aggregation of GalT that facilitates acrosomal exocytosis. This lead to the identification of two novel gamete receptors that appear to contribute to initial sperm-egg adhesion: sperm SED1 and the ZP3-independent ligand. These findings have enabled us to revise our earlier, and overly simplistic, model for GalT function during sperm-egg interactions (Fig. 3). We now hypothesize that SED1 and the ZP3-independent ligand, among other components such as FucT and/or $\alpha$-mannosidase, facilitate the initial adhesion between sperm and the ZP. This adhesion enables ZP3 oligosaccharides to interact with and aggregate GalT, which contributes to G-protein activation and acrosomal exocytosis. We suspect these components are just some of those that form a macromolecular adhesion and signaling complex, conceptually similar to the constellation of proteins that comprise other adhesion and signaling complexes, such as the Tcell receptor and focal adhesions. Clearly, this is simply a working model and no doubt will require revision as more detailed studies of SED1, the ZP3-independent ligand, FucT and other candidate receptors are conducted.

\section{Receptors for the ZP may be organized in macromo- lecular complexes in the sperm membrane}

One means by which cells regulate the association and function of multimeric macromolecular signaling complexes is to cluster the constituent proteins in a rigid lipid platform, or lipid raft, that remains intact in an otherwise fluid bilayer. Their rigidity is maintained by a characteristically high cholesterol content, so it is not surprising that the loss of cholesterol from the sperm membrane during capacitation leads to a reorganization of both the macromolecular components and spatial distribution of lipid rafts on the sperm head. This is well illustrated by a comparative analysis of proteins localized in rafts before and after capacitation (Sleight et al., 2005). It is of interest that one of the proteins found in lipid rafts isolated from porcine sperm is the sulfoglycolipid SGG discussed above that has been implicated in binding to the ZP (Khalil etal., 2006). The level of SGG associated with rafts increases during capacitation and correlates with an increased ability of rafts isolated from capacitated sperm to bind the ZP. It is thought, at least in porcine, that capacitation leads to a clustering of rafts on the apical sperm head, where the zonabinding machinery is concentrated for interaction with the ZP.

Molecular chaperones have long been known to be critical for the proper folding, transport and turnover of proteins, and several chaperones are found in mitotically-active spermatogenic cells. One chaperone that is expressed specifically during postmeiotic spermatogenic differentiation is calmegin, a testis-specific homolog of the endoplasmic reticulum chaperone, calnexin. Calmegin-dependent protein processing is required for sperm function, as shown by the inability of calmegin-null sperm to transport through the oviduct or bind the ZP (Ikawa et al., 1997). The loss of zona-binding ability may reflect the absence of ADAM3, a sperm surface protein discussed above implicated in sperm-zona binding and whose expression on mature sperm is calmegin-dependent (Yamaguchi et al., 2006). Surprisingly, some chaperones are found on the plasma membrane of a subpopulation of capacitated sperm, including heat-shock protein 60 (Hsp60) and endoplasmin. Although these chaperones are present in early spermatogenic cells, it is thought that the sperm-associated chaperones are derived from epididymal sections. Their expression on capacitated sperm suggest to Aitken and colleagues that they may be involved in the recruitment, organization and/or stabilization of sperm surface components required for subsequent interactions with the oviduct and/or binding to the ZP (Nixon et al., 2005).

\section{Concluding thoughts}

In light of the complex array of cellular and molecular events that culminate in fertilization, it is not surprising that many of the underlying molecular mechanisms have proven difficult to decipher. In vitro assays have been invaluable for the biochemical characterization of sperm and eggs, and provide a platform for the elucidation and testing of molecular models to account for species-specific gamete recognition. Nevertheless, in vitro assays fail to recapitulate the complex array of biochemical and physi-

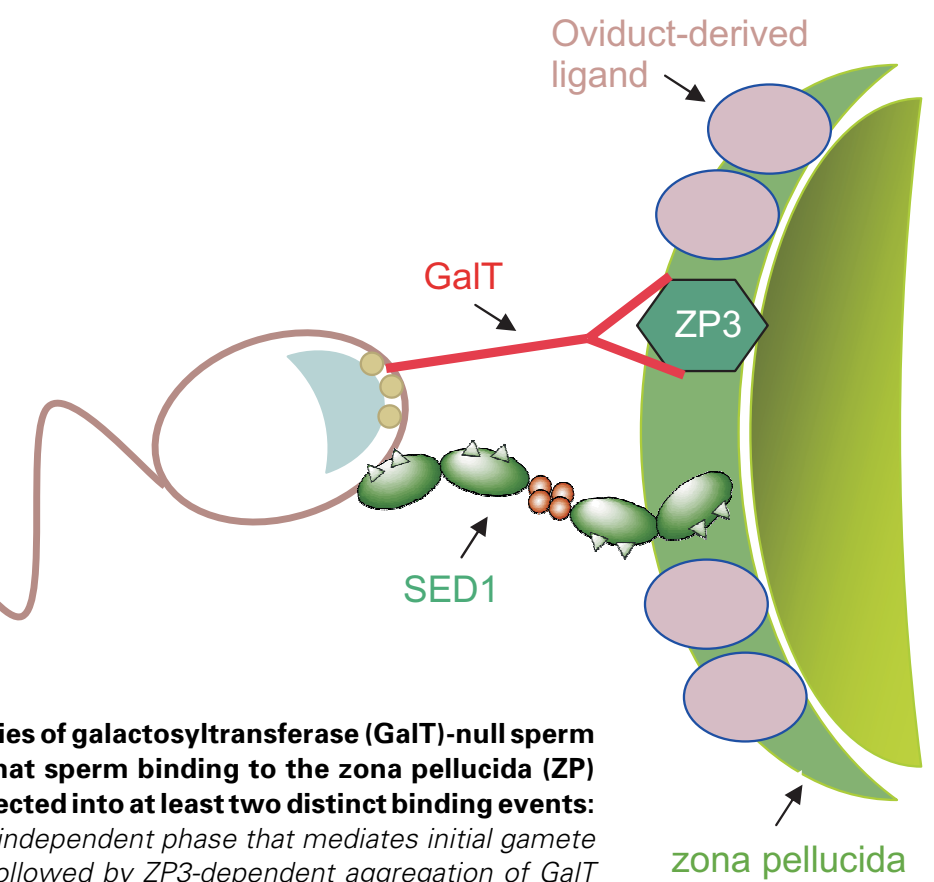

Fig. 3. Studies of galactosyltransferase (GaIT)-null sperm illustrate that sperm binding to the zona pellucida (ZP) can be dissected into at least two distinct binding events: a GalT/ZP3-independent phase that mediates initial gamete adhesion, followed by ZP3-dependent aggregation of GalT leading to acrosomal exocytosis. Although a GlcNAc-termi-

nating O-linked trisaccharide has been identified on $Z P 3$, it is not yet clear if it serves as the GalT-binding site in ZP3. Subsequent studies lead to the identification of SED1 as a sperm-associated protein that is required for initial binding to the ZP, as well as an oviduct-derived sperm-binding ligand that coats the ZP upon ovulation. The nature of the SED1 binding sites within the ZP remain unknown, as is the basis of sperm binding to the oviduct-derived ligand or its requirement for fertilization in vivo. This figure does not include many other sperm components that likely contribute to gamete binding, such as ADAM3, FucT, among others. (Figure adapted from Lyng and Shur, 2007). 
ological events that are required for successful fertilization. On the other hand, results of gene-targeting approaches must be interpreted with caution, since it is unknown how the protein of interest is impacted by gamete storage, maturation, activation, and transport.

It may be that too much emphasis has been put on the identification of a single, unique receptor-ligand interaction that is responsible for mammalian gamete binding. In this regard, studies from other systems have illustrated that cells which interact in a fluid, dynamic environment, as gametes do, must rely upon the sequential and coordinated action of distinct receptor-ligand interactions that culminate in tight association between the relevant cells (Sackstein, 2005). Likewise, it is now clear that spermegg interactions are also the consequence of multiple, distinct binding events, each presumably mediated by specific receptorligand interactions. A number of studies illustrate that multiple sperm plasma membrane proteins show binding affinity for the $\mathrm{ZP}$, consistent with zona binding being dependent on a multiplicity of sperm proteins. Interestingly, among those sperm proteins that bind the ZP are SED1, ADAM1, as well as other putative zonabinding proteins (van Gestel et al., 2007).

Furthermore, we may be too limited in how we think of proteincarbohydrate complementarity in sperm-ZP binding. Rather than binding to simple defined sugar residue extending out from the $\mathrm{ZP}$, it is more likely that sperm proteins recognize a 3-dimensional stereospecific presentation of highly branched glycans and/or charged residues, as has been shown for the sea urchin sperm receptor bindin that recognizes a specific sulfation pattern elaborated on egg coat glycoproteins (Vilela-Silva et al., 2002). In this regard, stereospecific polysulfations are known to dictate the binding specificity of a wide range of proteins, such as growth factor binding to proteoglycans (Hacker et al., 2005). Similar mechanisms have been proposed for the binding of proacrosin to the ZP (Gaboriau et al., 2007), as well as for SGG and SED1/ MFG-E8 interactions with their ZP ligands. In any event, our continued investigation of mammalian sperm-egg binding will benefit greatly from the lessons learned from the study of other systems, ranging from lymphocyte homing to sea urchin fertilization.

\section{References}

ABDULLAH, M. AND KIERSZENBAUM, A.L. (1989). Identification of rat testis galactosyl receptor using antibodies to liver asialoglycoprotein receptor: purification and localization on surfaces of spermatogenic cells and sperm. $J$ Cell Biol. 108:367-375.

ADHAM, I.M., NAYERNIA, K. ENGEL, W. (1997). Spermatozoa lacking acrosin protein show delayed fertilization. Mol. Reprod. Dev. 46: 370-376.

ARAKI, Y., NOHARA, M., YOSHIDA-KOMIYA, H., KURAMOCHI, T., ITO, M., HOSHI, H., SHINKAI, Y. AND SENDAI, Y. (2003). Effect of a null mutation of the oviduct-specific glycoprotein gene on mouse fertilization. Biochem. J. 374:551557.

AVILÉS, M., JABER, L., CASTELLS, M.T., BALLESTA, J. AND KAN, F.W.K. (1997). Modifications of carbohydrate residues and ZP2 and ZP3 glycoproteins in the mouse zona pellucida after fertilization. Biol. Reprod. 57: 1155-1163.

AVILÉS, M., CASTELLS, M.T., ABASCAL, I., MARTÍNEZ-MENÁRGUEZ, J.A., DRÁBER, P., KAN, F.W. AND BALLESTA, J. (1999). Cytochemical localization of GaINAc and GalNAcbeta1,4Galbeta1,4 disaccharide in mouse zona pellucida. Cell Tissue Res. 295:269-277.

AVILÉS, M., OKINAGA, T., SHUR, B.D. AND BALLESTA, J. (2000). Differential expression of glycoside residues in the mammalian zona pellucida. Mol.
Reprod. Dev. 57: 296-308.

BABA, T., AZUMA, S., KASHIWABARA, S. AND TOYODA, Y. (1994). Sperm from mice carrying a targeted mutation of the acrosin gene can penetrate the oocyte zona pellucida and effect fertilization. J. Biol. Chem. 269: 31845-31849.

BAIBAKOV, B., GAUTHIER, L., TALBOT, P., RANKIN, T.L. AND DEAN, J. (2007). Sperm binding to the zona pellucida is not sufficient to induce acrosome exocytosis. Development. 134:933-943.

BENAU, D.A., MCGUIRE, E.J. AND STOREY, B,T. (1990). Further characterization of the mouse sperm surface zona-binding site with galactosyltransferase activity. Mol. Reprod. Dev. 25: 393-399.

BENDAHMANE, M. AND TULSIANI, D.R. (2003). Capacitated acrosome-intact mouse spermatozoa bind to Sepharose beads coated with functional neoglycoproteins. Arch Biochem Biophys. 415:203-212.

BLEIL, J.D. AND WASSARMAN, P.M. (1980a). Mammalian sperm-egg interaction: identification of a glycoprotein in mouse egg zonae pellucidae possessing receptor activity for sperm. Cel/20: 873-882.

BLEIL, J.D. AND WASSARMAN, P.M. (1980b). Structure and function of the zona pellucida: identification and characterization of the proteins of the mouse oocytes zona pellucida. Dev. Biol. 76: 185-202.

BLEIL, J.D. AND WASSARMAN, P.M. (1983). Sperm-egg interactions in the mouse: sequence of events and induction of the acrosome reaction by a zona pellucida glycoprotein. Dev. Biol. 95: 317-324.

BLEIL, J.D. AND WASSARMAN, P.M. (1988). Galactose at the nonreducing terminus of $O$-linked oligosaccharides of mouse egg zona pellucida glycoprotein ZP3 is essential for the glycoprotein's sperm receptor activity. Proc. Nat/. Acad. Sci. USA 85: 6778-6782.

BLEIL, J.D. AND WASSARMAN, P.M. (1990). Identification of a ZP3-binding protein on acrosome-intact mouse sperm by photoaffinity crosslinking. Proc. Natl. Acad. Sci. USA 87: 5563-5567.

BUSSO, D., COHEN, D.J., MALDERA, J.A., DEMATTEIS, A. AND CUASNICU, P.S. (2007) A novel function for CRISP1 in rodent fertilization: involvement in sperm-zona pellucida interaction. Biol. Reprod. 77: 848-854.

CAHOVÁ, M. AND DRÁBER, P. (1992). Inhibition of fertilization by a monoclonal antibody recognizing the oligosaccharide sequence GalNAc beta 1-4Gal beta 1-4 on the mouse zona pellucida. J Reprod Immunol. 21:241-256.

CHALABI, S., PANICO, M., SUTTON-SMITH, M., HASLAM, S.M., PATANKAR, M.S., LATTANZIO, F.A., MORRIS, H.R., CLARK, G.F. AND DELL, A. (2006) Differential O-glycosylation of a conserved domain expressed in murine and human ZP3. Biochemistry. 45:637-647.

CHIU, P.C.N., CHUNG, M.-K., KOISTINEN, R., KOISTINEN, H., SEPPALA, M., HO, P.-C., NG, E.H.Y., LEE, K.-F. AND YEUNG, W.S.B. (2007). Glycodelin-A interacts with fucosyltransferase on human sperm plasma membrane to inhibit spermatozoa-zona pellucida binding. J. Cell Sci. 120:33-44.

CLARK, G.F. AND DELL, A. (2006). Molecular models for murine sperm-egg binding. J. Biol. Chem. 281: 13853-13856.

CORNWALL, G.A., TULSIANI, D.R.P. AND ORGEBIN-CRIST, M.C. (1991). Inhibition of the mouse sperm surface a-D-mannosidase inhibits sperm-egg binding in vitro. Biol. Reprod. 44: 913-921.

DELL, A., MORRIS, H.R., EASTON, R.L., PANICO, M., PATANKAR, M., OEHNIGER, S., KOISTINEN, R., KOISTINEN, H., SEPPALA, M. AND CLARK, G.F. (1995). Structural analysis of the oligosaccharides derived from glycodelin, a human glycoprotein with potent immunosuppressive and contraceptive activities. $J$. Biol. Chem. 270:24116-24126.

DELL, A., CHALABI, S., EASTON, R.L., HASLAM, S.M., SUTTON-SMITH, M., PATANKAR, M.S., LATTANZIO, F., PANICO, M., MORRIS, H.R. AND CLARK, G.F. (2003). Murine and human zona pellucida 3 derived from mouse eggs express identical O-glycans. Proc. Natl. Acad. Sci. USA 100: 15631-15636.

EASTON, R.L., PATANKAR, M.S., LATTANZIO, F.A., LEAVEN, T.H., MORRIS, H.R., CLARK, G.F. AND DELL, A. (2000). Structural analysis of murine zona pellucida glycans. Evidence for the expression of core 2-type O-glycans and the Sda antigen. J. Biol. Chem. 275: 7731-7742.

ENSSLIN, M., VOGEL, T., CALVETE, J.J., THOLE, H.H., SCHMIDTKE, J. AND TÖPFER-PETERSEN, E. (1998). Molecular cloning and characterization of $\mathrm{P} 47$, a novel boar sperm-associated zona pellucida-binding protein homologous to a family of mammalian secretory proteins. Biol. Reprod. 58: 1057-1068.

ENSSLIN, M.A. AND SHUR, B.D. (2003). Identification of mouse sperm SED1, a bi- 
motif EGF repeat and discoidin domain protein involved in sperm-egg binding. Cel/ 114: 405-417.

FAYRER-HOSKEN, R.A., CAUDLE, A.B. AND SHUR, B.D. 1991. Galactosyltransferase activity is restricted to the plasma membranes of equine and bovine sperm. Molec. Reprod. Devel. 28: 74-78.

FLORMAN, H.M. AND WASSARMAN, P.M. (1985). Olinked oligosaccharides of mouse egg ZP3 account for its sperm receptor activity. Ce//41: 313-324.

FLORMAN, H.M., ARNOULT, C., KAZAM, I.G., LI, C. AND O'TOOLE, C.M.B. (1999). An intimate biochemistry: egg-regulated acrosome reactions of mammalian sperm. Adv. Dev. Biochem. 5: 199-233.

FUENTES-PRIOR, P., FUJIKAWA, K. AND PRATT, K.P. (2002). New insights into binding interfaces of coagulation factors $\mathrm{V}$ and VIII and their homologues lessons from high resolution crystal structures. Curr. Prot. Pep. Sci. 3:313-339.

GABORIAU, D., HOWES, E.A., CLARK, J. AND JONES, R. (2007) Binding of sperm proacrosin/beta-acrosin to zona pellucida glycoproteins is sulfate and stereodependent. Synthesis of a novel fertilization inhibitor. Dev Biol. 306:646657.

GONG, X., DUBOIS, D.H., MILLER, D.J. AND SHUR, B.D. (1995) Activation of a G-protein complex by aggregation of $\beta 1,4$-galactosyltransferase on the surface of sperm. Science 269: 1718-1721.

HACKER, U., NYBAKKEN, K. AND PERRIMON, N. (2005) Heparan sulphate proteoglycans: the sweet side of development. Nat Rev Mol Cell Biol. 6: 530541.

HARDY, D.M. (2000). Structure, activity, and species-diversity of zonadhesin. The Third International Symposium on the Molecular and Cellular Biology of the Egg and Embryo Extracellular Matrix. Abstract II1.

HARDY, D.M. AND GARBERS, D.L. (1995). A sperm membrane protein that binds in a species-specific manner to the egg extracellular matrix is homologous to von Willebrand factor. J. Biol. Chem. 270: 26025-26028.

HOODBHOY, T. AND DEAN, J. (2004). Insights into the molecular basis of sperm - egg recognition in mammals. Reproduction 127: 417-422.

HOODBHOY T, JOSHI S, BOJA ES, WILLIAMS SA, STANLEY P, DEAN J. (2005) Human sperm do not bind to rat zonae pellucidae despite the presence of four homologous glycoproteins. J Biol Chem. 280:12721-12731.

HUSZAR, G., SBRACIA, M., VIGUE, L., MILLER, D.J., AND SHUR, B.D. (1997). Sperm plasma membrane remodeling during spermiogenetic maturation in men: relationship among plasma membrane $\beta 1$,4-galactosyltransferase, cytoplasmic creatine phosphokinase, and creatine phosphokinase isoform ratios. Bio. Reprod. 56: 1020-1024.

IKAWA, M., WADA, I., KOMINAMI, K., WATANABE, D., TOSHIMORI, K., NISHIMUNE, Y. AND OKABE, M. (1997). The putative chaperone calmegin is required for sperm fertility. Nature 387: 607-611.

JOHNSTON, D.S., WRIGHT, W.W., SHAPER, J.H., HOKKE, C.H., VAN DEN EIJINDEN, D.H. AND JOZIASSE, D.H. (1998). Murine sperm-zona binding, a fucosyl residue is required for a high affinity sperm-binding ligand. A second site on sperm binds a nonfucosylated, $\beta$-galactosyl-capped oligosaccharide. J. Biol. Chem. 278: 1888-1895.

KERR, C.L., HANNA, W.F., SHAPER, J.H. AND WRIGHT, W.W. (2004). Lewis Xcontaining glycans are specific and potent competitive inhibitors of the binding of ZP3 to complementary sites on capacitated, acrosome-intact mouse sperm. Biol. Reprod. 71: 770-777.

KHALIL, M.B., CHAKRABANDHU, K., XU, H., WEERACHATYANUKUL, W., BUHR, M., BERGER, T., CARMONA, E., VUONG, N., KUMARATHASAN, P., WONG, P.T.T., CARRIER, D., AND TANPHAICHITR, N. (2006). Sperm capacitation induces an increase in lipid rafts having zona pellucida binding ability and containing sulfogalactosylglycerolipid. Dev. Biol. 290: 220-235

LARSON, J.L. AND MILLER, D.J. (1997). Sperm from a variety of mammalian species express beta1,4-galactosyltransferase on their surface. Biol Reprod. 57:442-453.

LEYTON, L. AND SALING, P. (1989). $95 \mathrm{kd}$ sperm proteins bind ZP3 and serve as tyrosine kinase substrates in response to zona binding. Cel/57: 1123-113.

LILLIE, F.R. (1913). The mechanism of fertilization. Science 38: 524-528.

LITSCHER, E.S., SUNTUNEN, K., SEPPO, A., PENTTILA, L., NIEMELA, R., RENKONEN, O. AND WASSARMAN, P.M. (1995). Oligosaccharide constructs with defined structures that inhibit binding of mouse sperm to unfertilized eggs in vitro. Biochemistry 34: 4662-4669.
LOPEZ, L.C., BAYNA, E.M., LITOFF, D., SHAPER, N.L., SHAPER, J.H. AND SHUR, B.D. (1985). Receptor function of mouse sperm surface galactosyltransferase during fertilization. J. Cell Biol. 101: 1501-1510.

LU, Q. AND SHUR, B.D. (1997). Sperm from $\beta 1$,4-galactosyltransferase null mice are refractory to ZP3-induced acrosome reactions and penetrate the zona pellucida poorly. Development 124: 4121-4131.

LYNG, R. AND SHUR, B.D. (2007). Sperm-egg binding requires a multiplicity of receptor-ligand interactions: new insights into the nature of gamete receptors derived from reproductive tract secretions. Soc Reprod Fertil Suppl. 65:335351.

MA, B., SIMALA-GRANT, J.L. AND TAYLOR, D.E. (2006). Fucosylation in prokaryotes and eukaryotes. Glycobiology 16:158R-184R.

MACEK, M.B., LOPEZ, L.C., AND SHUR, B.D. (1991). Aggregation of $\beta 1,4$ galactosyltransferase on mouse sperm induces the acrosome reaction. Dev. Biol. 147: 440-444.

MALETTE, B., PAQUETTE, Y., MERLEN, Y. AND BLEAU, G. (1995). Oviductins possess chitinase- and mucin-like domains: a lead in the search for the biological function of these oviduct-specific ZP-associating glycoproteins. Mol. Reprod. Devel. 41: 384-397.

MEIZEL, S. (1997). Amino acid neurotransmitter receptor/chloride channels of mammalian sperm and the acrosome reaction. Biol. Reprod. 56: 569-574.

MILLER, D.J., GONG, X., DECKER., G. AND SHUR, B.D. (1993b). Egg cortical granule $N$-acetylglucosaminidase is required for the mouse zona block to polyspermy. J. Cell Biol. 123: 1431-1440.

MILLER, D.J., MACEK, M.B. AND SHUR, B.D. (1992). Complementarity between sperm surface $\beta \mathrm{I}, 4$ galactosyltransferase and egg coat ZP3 mediates spermegg binding. Nature 357: 589-593.

MORI, E., MORI, T. AND TAKASAKI, S. (1997) Binding of mouse sperm to betagalactose residues on egg zona pellucida and asialofetuin-coupled beads. Biochem. Biophys. Res. Commun. 238: 95-99.

MORTILLO, S. AND WASSARMAN, P.M. (1991). Differential binding of goldlabeled zona pellucida glycoproteins mZP2 and mZP3 to mouse sperm membrane compartments. Development. 113: 141-149.

NAGDAS, S.K., ARAKI, Y., CHAYKO, C.A., ORGEBIN-CRIST, M.C. AND TULSIANI, D.R.P. (1994). O-linked trisaccharide and $N$-linked poly- $N$-acetyllactosaminyl glycans are present on mouse ZP2 and ZP3. Biol. Reprod. 51: 262-272.

NEILL, A.T. AND VACQUIER, V.D. (2004). Ligands and receptors mediating signal transduction in sea urchin spermatozoa. Reproduction. 127:141-149.

NISHIMOTO, I., OKAMOTO, T., MATSUURA, Y., TAKAHASHI, S., OKAMOTO, T., MURAYAMA, Y. AND OGATA, E. (1993). Alzheimer amyloid protein precursor complexes with brain GTP-binding protein $\mathrm{G}_{0}$. Nature 362: 75-79.

NISHIMURA, H., CHO, C., BRANCIFORTE, D.R., MYLES, D.G. AND PRIMAKOFF, $P$. (2001) Analysis of loss of adhesive function in sperm lacking cyritestin or fertilin beta. Dev Biol. 233:204-213.

NISHIMURA, H., MYLES, D.G. AND PRIMAKOFF, P. (2007). Identification of an ADAM2-ADAM3 complex on the surface of mouse testicular germ cells and cauda epididymal sperm. J. Biol. Chem. 282:17900-17907.

NIXON, B., ASQUITH, K.L., AND AITKEN, R.J. (2005). The role of molecular chaperones in mouse sperm-egg interactions. Mol. Cell. Endocrinol. 240: 1-10.

NOGUCHI, S. AND NAKANO, M. (1993). Structural characterization of the N-linked carbohydrate chains from mouse zona pellucida glycoproteins ZP2 and ZP3. Biochim Biophys Acta. 1158:217-226.

OKAMOTO, T., KATADA, T., MURAYAMA, Y., UI, M., OGATA, E. AND NISHIMOTO I. (1990). A simple structure encodes G-protein activating function of the IGFII mannose 6-phosphate receptor. Cel/62: 709-717.

OKAMOTO, T., TAKEDA, S., MURAYAMA, Y., OGATA, E. AND NISHIMOTO, I. (1993). Ligand-dependent $G$ protein coupling function of amyloid transmembrane precursor. J Biol Chem 270: 4205-4208.

ORR, A.W., HELMKE, B.P., BLACKMAN, B.R. AND SCHWARTZ, M.A. (2006) Mechanisms of mechanotransduction. Dev. Cel/10:11-20.

RANKIN, T.L., TONG, Z.-B., CASTLE, P.E., LEE, E., GORE-LANGTON, R., NELSON, L.M. AND DEAN, J. (1998). Human ZP3 restores fertility in Zp3 null mice without affecting order-specific sperm binding. Development 125: 2415 2424.

RIVKIN, E., TRES, L.L., KAPLAN-KRAICER, R., SHALGI, R. AND KIERSZENBAUM 
A.L. (2000) Molecular cloning of rat sperm galactosyl receptor, a C-type lectin with in vitro egg binding activity. Mol. Reprod. Devel. 56: 401-411.

RODEHEFFER, C. AND SHUR, B.D. (2002). Targeted mutations in $\beta 1,4$ galactosyltransferase I reveal its multiple cellular functions. Biochim. Biophys. Acta Reviews 1573: 258-270.

RODEHEFFER, C. AND SHUR, B.D. (2004). Identification of a novel, ZP3independent egg coat ligand that facilitates initial sperm-egg adhesion. Deve/opment 131: 503-512.

SACKSTEIN, R. (2005). The lymphocyte homing receptors: gatekeepers of the multistep paradigm. Curr Opin Hematol. 12:444-450.

SCULLY, N.F., SHAPER, J.H., AND SHUR, B.D. (1987) Spatial and temporal expression of cell surface galactosyltransferase during mouse spermatogenesis and epididymal maturation. Dev Biol. 124:111-124.

SENDAI, Y., KOMIYA, H., SUZUKI, K., ONUMA, T., KIKUCHI, M., HOSHI, H. AND ARAKI, Y. (1995). Molecular cloning and characterization of a mouse oviductspecific glycoprotein. Biol. Reprod. 53: 285-94.

SHAMSADIN, R., ADHAM, I.M., NAYERNIA, K., HEINLEIN, U.A., OBERWINKLER, H. AND ENGEL, W. (1999). Male mice deficient for germ-cell cyritestin are infertile. Biol Reprod. 61:1445-1451.

SHI, S., WILLIAMS, S.A., SEPPO, A., KURNIAWAN, H., CHEN, W., YE, Z., MARTH, J.D. AND STANLEY, P. (2004). Inactivation of the Mgat1 gene in oocytes impairs oogenesis, but embryos lacking complex and hybrid N-glycans develop and implant. Mol Cel/ Biol. 24:9920-9999.

SHI, X., AMINDARI, S., PARUCHURU, K., SKALLA, D., SHUR, B.D. AND MILLER, D.J. (2001) Cell surface $\beta 1$,4-galactosyltransferase-I activates $G$ protein-dependent exocytotic signaling. Development 128: 645-654.

SHUR, B.D. AND HALL, N.G. (1982a). Sperm surface galactosyltransferase activities during in vitro capacitation. J. Cell Biol. 95: 567-573.

SHUR, B.D. AND HALL, N.G. (1982b). A role for mouse sperm surface galactosyltransferase in sperm binding to the egg zona pellucida. J. Cell Biol. 95: 574-579.

SHUR, B.D. AND NEELY, C.A. (1988). Plasma membrane association, purification and characterization of mouse sperm $\beta 1,4$ galactosyltransferase. J. Biol. Chem. 263: 17706-17714.

SHUR, B.D., ENSSLIN, M.A. AND RODEHEFFER, C. (2004). SED1 function during mammalian sperm-egg adhesion. Curr Opin Cell Bio/16:477-485.

SHUR, B.D., RODEHEFFER, C., ENSSLIN, M.A., LYNG, R., AND RAYMOND, A. (2006) Identification of novel gamete receptors that mediate sperm adhesion to the egg coat. Mol Cell Endocrinol. 250:137-148.

SLEIGHT, S.B., MIRANDA, P.V., PLASKETT, N.-W., MAIER, B., LYSIAK, J., SCRABLE, H., HERR, J.C. AND VISCONTI, P.E. (2005). Isolation and proteomic analysis of mouse sperm detergent-resistant membrane fractions: evidence for dissociation of lipid rafts during capacitation. Biol. Reprod. 73: 721-729.

SUN, H., SEYER, J.M., AND PATEL, T.B. (1995). A region in the cytosolic domain of the epidermal growth factor receptor antithetically regulates the stimulatory and inhibitory guanine nucleotide-binding regulatory proteins of adenylyl cyclase. Proc Nat/ Acad Sci USA. 92:2229-2233.

THALER, C.D. AND CARDULLO, R.A. (1996). Defining oligosaccharide specificity for initial sperm-zona pellucida adhesion in the mouse. Molec. Reprod. Devel. 45:535-546.

TULSIANI, D.R., SKUDLAREK, M.D. AND ORGEBIN-CRIST, M.C. (1989). Novel
alpha-D-mannosidase of rat sperm plasma membranes: characterization and potential role in sperm-egg interactions. J Cell Biol. 109:1257-1267.

TULSIANI, D.R. (2000). Structural analysis of the asparagine-linked glycan units of the ZP2 and ZP3 glycoproteins from mouse zona pellucida. Arch Biochem Biophys. 382:275-283.

TULSIANI, D.R.P., NAGDAS, S.K., CORNWALL, G.A. AND ORGEBIN-CRIST, M.C. (1992). Evidence for the presence of high mannose/hybrid oligosaccharide chain(s) on the mouse ZP2 and ZP3. Biol. Reprod. 46: 93-100.

TULSIANI, D.R.P., YOSHIDA-KOMIYA, H. AND ARAKI, Y. (1997). Mammalian fertilization: a carbohydrate-mediated event. Biol. Reprod. 57: 487-494.

VAN GESTEL, R.A., BREWIS, I.A., ASHTON, P.R., BROUWERS, J.F. AND GADELLA, B.M. (2007). Multiple proteins present in purified porcine sperm apical plasma membranes interact with the zona pellucida of the oocyte. Mol. Hum. Reprod. 13:445-454.

VERHAGE, H.G., MAVROGIANIS, P.A., O'DAY-BOWMAN, M.B., SCHMIDT, A., ARIAS, E.B., DONNELLY, K.M., BOOMSMA, R.A., THIBODEAUX, J.K., FAZLEABAS, A.T., AND JAFFE, R.C. (1998). Characteristics of an oviductal glycoprotein and its potential role in the fertilization process. Biol. Reprod. 58: 1098-1101.

VILELA-Silva, A. C., CAStRO, M. O., VALENTE, A. P., BIERMANN, C. H. AND MOURAO, P. A. (2002) Sulfated fucans from the egg jellies of the closely related sea urchins Strongylocentrotus droebachiensis and Strongylocentrotus pallidus ensure species-specific fertilization. J Biol Chem 277: 379-87.

WADE, S.M., LIM, W.K., LAN, K.-L., CHUNG, D.A., NANAMORI, M. AND NEUBIG, R.R. (1999). $G_{i}$ activator region of $\alpha_{2 A}$-adrenergic receptors: distinct basic residues mediate $G_{i}$ versus $G_{s}$ activation. Mol. Pharmacol. 56: 1005-1013.

WARD, C.R. AND KOPF, G.S. (1993). Molecular events mediating sperm activation. Dev. Biol. 158: 9-34.

WHITE, D., WEERACHATYANUKUL, W., GADELLA, B., KAMOLVARIN, N., ATTAR, M. AND TANPHAICHITR, N. (2000). Role of sperm sulfogalactosylglycerolipid in mouse sperm-zona pellucida binding. Biol. Reprod. 63: 147-155.

WILLIAMS, S.A., XIA, L., CUMMINGS, R.D., MCEVER, R.P., AND STANLEY, P. (2007) Fertilization in mouse does not require terminal galactose or $\mathrm{N}$ acetylglucosamine on the zona pellucida glycans. J Cell Sci. 120:1341-1349.

YAMAGATA, T. (1985). The role of saccharides in fertilization of the mouse. Dev. Growth Differ. 27: 176-177.

YAMAGUCHI, R., YAMAGATA, K., IKAWA, M., MOSS, S.B. AND OKABE, M. (2006). Aberrant distribution of ADAM3 in sperm from both angiotensin-converting enzyme $(A c e)$ - and calmegin (Clgn)-deficient mice. Biol Reprod. 75:760766.

YONEZAWA, N., AOKI, H., HATANAKA, Y. AND NAKANO, M. (1995). Involvement of $N$-linked carbohydrate chains of pig zona pellucida in sperm-egg binding. Eur. J. Biochem. 233: 35-41.

YONEZAWA, N., KANAI, S. AND NAKANO, M. (2007). Structural significance of Nglycans of the zona pellucida on species-selective recognition of spermatozoa between pig and cattle. Soc Reprod Fertil Suppl. 63:217-228.

YOUAKIM, A., HATHAWAY, H.J., MILLER, D.J., GONG, X. AND SHUR, B.D. (1994). Overexpressing sperm surface $\beta 1,4$ galactosyltransferase in transgenic mice affects multiple aspects of sperm-egg interactions. J. Cel/ Biol. 126: 15731584. 


\section{Related, previously published Int. J. Dev. Biol. articles}

See our recent Special Issue Developmental Biology in Poland edited by Tarkowski, Maleszewski and Kloc at: http://www.ijdb.ehu.es/web/contents.php?vol=52\&issue =2-3

See our recent Special Issue Ear Development edited by Fernando Giraldez and Bernd Fritzsch at: http://www.ijdb.ehu.es/web/contents.php?vol=51\&issue=6-7

Glycobiology of fertilization in the pig

Edda Töpfer-Petersen, Mahnaz Ekhlasi-Hundrieser and Miroslava Tsolova

Int. J. Dev. Biol. (2008) 52: 717-736

Mammalian fertilization:the egg's multifunctional zona pellucida

Paul M. Wassarman and Eveline S. Litscher

Int. J. Dev. Biol. (2008) 52: 2524-2524

Genetic control of gamete quality in the mouse - a tribute to Halina Krzanowska

Jozefa Styrna

Int. J. Dev. Biol. (2008) 52: 195-199

Molecular aspects of avian oogenesis and fertilisation

Bozenna Olszanska and Urszula Stepinska

Int. J. Dev. Biol. (2008) 52: 187-194

Distinct mechanisms underlie sperm-induced and protease-induced oolemma block to sperm penetration.

Sebastian Komorowski, Katarzyna Szczepanska and Marek Maleszewski

Int. J. Dev. Biol. (2003) 47: 65-69

CpZPC, a newt ZPC molecule, localizes to the inner surface of the egg envelope. Youko Makabe-Kobayashi, Etsuko Kudaira, Akihiko Watanabe and Kazuo Onitake Int. J. Dev. Biol. (2003) 47: 51-58

Association of egg zona pellucida glycoprotein mZP3 with sperm protein sp56 during fertilization in mice.

$\mathrm{N}$ Cohen and $\mathrm{P} M$ Wassarman

Int. J. Dev. Biol. (2001) 45: 569-576

Alcohol consumption during pregnancy alters glycoconjugates, galactosyltransferase activity and beta-COP proteins in the Golgi apparatus of hepatocytes in developing liver.

J M Seguí, R Guasch, I Azorin, C Guerri and J Renau-Piqueras

Int. J. Dev. Biol. (1996) 40: S285-S286

Analysis of polysulfate-binding domains in porcine proacrosin, a putative zona adhesion protein from mammalian spermatozoa.

$S$ Jansen, M Quigley, W Reik and R Jones

Int. J. Dev. Biol. (1995) 39: 501-510

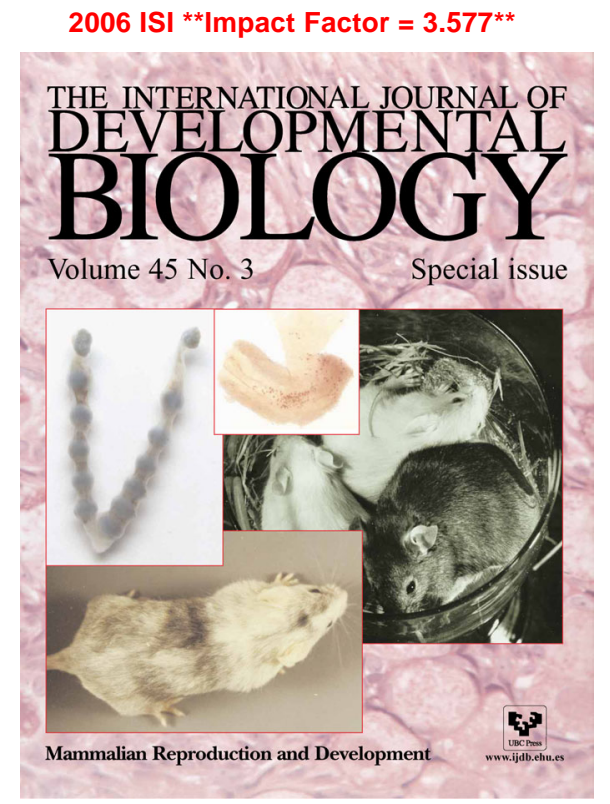

